\title{
Hypomyelination with atrophy of basal ganglia and cerebellum
}

INSERM

\section{Source}

INSERM. (1999). Orphanet: an online rare disease and orphan drug data base. Hypomyelination with atrophy of basal ganglia and cerebellum. ORPHA:139441

Hypomyelination with atrophy of basal gang lia and cerebellum $(\mathrm{H}-\mathrm{ABC})$ is characterized by slowly progressive spasticity, extrapyramidal movement disorders (dystonia, choreoathetosis and rigidity), cerebellar ataxia, moderate to severe cog nitive deficit, and anarthria/dysarthria. 